\title{
sciendo
}

\section{Rethinking leadership models after COVID-19}

\author{
Teodora ABRAMIUC (TODORAN) \\ Bucharest University of Economic Studies, Bucharest, Romania \\ teodora_todoran@yahoo.com \\ Raluca Andreea POPA \\ Bucharest University of Economic Studies, Bucharest, Romania \\ raluca.popa@economie.ase.ro
}

\begin{abstract}
Leadership models in the times of COVID-19 is surely the topic of the hour, yet this hour might last for some few years. By the end of it, we will reach the point of no return and a new set of rules and paradigms would have been created. Many researchers and leadership representatives investigate this topic. The available and reviewed literature is rather shaping the discrepancies of the past-embedded practices, as opposed to the current challenges. In this context of constant change, the current paper is aiming to investigate some current leadership practices, which are targeting the level of productivity, different ways of working and communicating in the work from home context. Moreover, the research would be setting the stage for something that is not there yet, in the current leadership patterns. The research methodology based on top management and senior leaders' interviews, covering multiple industries from Romania, like banking, energy, manufacturing at large scale and outsourcing. The questions were designed to investigate the realities on their new job definition, from a personal perspective, as people managers and the business value outcomes envisioned in the new scheme of work. The theoretical contribution of the paper is to define a set of guidelines and filtering areas of leadership focus. The set of information gathered for new business metrics of performance, the ownership, efficiency and business value creation is pushed at all levels. One major change is the new definition of discipline, shifting from authority into entrepreneurial attitudes.
\end{abstract}

Keywords: Leadership model, COVID-19, Sustainability, Business environment, Post pandemic, Culture, Innovation.

\section{Introduction}

This paper while it has elements of past researches, which are bringing a great set of value to understand where leaders are positioned, or the skills and values they carry as their legacy, it is at the same time trying to contribute to the unforeseen and hard to imagine the future context. Hence, the below chapters and ideas will add on to the efforts of similar researchers, scientist in the field of adjusting in the new norms, and also bring a new perspective of two separate dimensions.

One dimension is the "NOW" in which leaders are performing or struggling to keep up with the organizations, expectations, people and human complexities of managing teams and economical challenges.

The second dimension is "Future". Professionals around the globe are facing the same challenges and uncertainties into preparing for what is there to come. Nevertheless, that does not mean that the scholars, intellectuals, organizations, universities and all meaningful forums and institutions are not already working into preparing for the unknowns. The preparation is almost like creating the unknown.

For the above reasons, at least, the current paper has taken a leap of faith into generating future theories and expectations to be more prepared for handling the "Now" and adapting for the 
new way of working, simply put the "Future" dimension. Basis existing theories and knowledge on the past and current leadership models, the authors have interviewed a set of leaders from various industries or sectors and understood at first hand the practices that are either in a frozen state, emerging new habits or disruptive thinking. All of these are predictors of the future dimension. The expectation of the paper was, as stated above, to provide a snapshot of the present and to bring to surface what are the predictive elements of a future behavior and attitudes of the leaders. The interviews conducted have interrogated elements linked to employees' experience basis: leadership practices and their results and actions in terms of productivity, at an observable level, or measured through various metrics.

\section{Literature review}

Since the last century, enterprises and governments were driven by the idea of profit maximization. Microeconomics discipline was focusing on different models and theories in how firms can maximize profits bringing at the center the free market concept, private enterprises, deregulation, taxation, expenditure. We cannot contradict that the society functions better in a free market basis, and leaders are motivated by profit maximization making this central goal. This was called neoliberal leadership paradigm and there are plenty of researcher that studied this topic. According to the researcher neoliberal leadership appeared in the early 1970's due to the gap of productivity between American and Japanese companies (Johnson \& Ouchi, 1974), Japanese companies made the world look different and the main characteristics of production / providing services became flexibility, variety and customization (Masayuki, 1998). Milton Freeman's monetarist theory of economics had also a contribution to this new way of seeing leadership and business environment.

Monetarism, which is related to neoliberalism underlines that the market should play the main role in business and governments, should have a minimal role in interfering on the market and on how private enterprises should act and work. This two schools of thinking, monetarism and neoliberalism, had a crucial role in rising a new generation of organizational leaders that made profit not their first objective but the only objective. In the past 10 years, many international organizations started to bring in the front the idea of sustainability also at business level, many big enterprises being guilty for producing negative externalities in their pursuit for profit maximization.

Nowadays it became more and more central the topic of sustainability at business level. The goal of Profit maximization started to be placed second and other two Ps took place: People and Planet. We could say that the pursuit for profit maximization was replaced by the pursuit of sustainability translated at the firm level by a different way to lead, closer to people and environment and also by corporate social responsibility. In the context of Covid pandemic, leaders and enterprises received this new challenge and changing the way of doing business became a burning subject. Leaders should get more involved in a positive way at the level of society and to assume the social role (Ghoshal et al., 1999) and re-frame leadership (Howieson et al., 2019). Howieson et al. see corporate culture as an important obstacle to achieve sustainability at enterprise level. Corporate culture being closely related to leadership change to corporate culture becomes a consequence of collaborative 'meaning-making' in practice. More change in leadership may be seen as a change at the collective model of leadership that at the individual level (Ospina, Foldy, 2010). Effective organizations require effective leaders. While many enterprises may recruit such leaders (i.e., "buy talent"), the best organizations understand that remaining competitive requires developing leadership capacity as a core business function (Wallace et al., 2021). 
There are more than 49 theories on leadership nowadays (Meuser et al., 2016) and according to Avolio et al.'s (2009) review paper entitled "Leadership: Current theories, research, and future directions" there are developed 13 major leadership theories. Zhu et al. (2019) made a map to see the network of major leadership constructs used in 200 landmark leadership documents. According to them, the Transformational leadership is at the heart of the network map. The lines are thicker between the constructs of transformational leadership, transactional leadership, charismatic leadership, and trait theories, which means that these leadership theories have a high level of co-occurrence, as seen in the leadership network map.

We could say that even if these theories refer to transformational and charismatic leadership, leader-member exchange and relational leadership, value-based forms of leadership, team leadership, trait leadership theories, strategic leadership, empowering and participative leadership, leadership emergence and development, followership, abusive supervision, identitybased leadership theories, emotions and leadership, diversity and cross-cultural leadership or other nascent leadership themes. They all tend to change and search recently a common point that can guide the corporate world through this new crisis, pandemic period. Nothing seems to be very valid in this new context and the trend is that all these theories should be revised.

Enterprises do their best to cope with emergencies and critical events to keep their reputation, be more resilient, and ensure continuity (Parker \& Ameen, 2018; Rezaei Soufi et al., 2019). We may say that leadership models have evolved since 1970 s as a way to manage crisis as a response to different risks that threaten the company.

Moving forward there are already new researches on the topic of the new leadership models, as per Colovic (2021) regarding new and innovative models of leadership. Trying to put the puzzle together McKinsey \& Company have conducted several relevant research studies and global surveys during the pandemic with various topics considered, to shape up the puzzle of the economy. The multiple available sources are tackling subjects like psychological safety and leadership development (De Smet et al., 2021), global surveys on business implications of the pandemic and the predictions of the economy on a range of 6 months (Craven et al., 2021) and even predictions of the ending of the pandemic, or better yet in the original title" When will the COVID-19 pandemic end?" (Charumilind et al., 2021). All such sources bring to attention one central element, the pandemic effect on multiple levels: business and economy, culture and people. More specific COVID-19 affected enterprises in how they operate searching for new ways to face the changes in supply chain, shift of demand, and risks regarding health and safety of employees.

\section{Methodology}

Academic interest in how organizations respond to crisis has strongly developed in the last years. The paper is centered more on the changes that can be done regarding employees and workplace and not on customer experience, logistic flows, continuing manufacturing process. While the above data is placing the business and economy in to the current reality, facing people challenges is a relevant factor to the current paper. People and psychological factors, medical challenges and insecurities, economical limitations of curating and keeping healthy the global population, all these are facts are the scenery around the day-to-day practices and ways of working for the people and companies. Not being part of the mechanism of healing or curing, planning or fighting COVID-19, means that the collateral damage is a standard of living the present. The context created, which is driven by psychological factors like fear and uncertainty, is demanding people to adapt to the unknown and this facts or factors have already started to reshape the human behavior. It is well known that the society sets the rules, that the cultures of the organizations are changing people's 
practices and in most critical situations even an entire system of values, mechanism of believes, driving them to reshape their entire definition as individuals. Often this is washing off the uniqueness and authenticity of individuals, forcing them to fit into the predefined shaped. Also known to be a concept in the book of Petrescu' s novel (1933), called "Patul lui Procust", yet inspired from the Greek mythology, the rogue smith and bandit from Attica, Procrustes.

The cultural element mixed with the organizational climate is another aspect considered as core knowledge to the current topic. It has strong implications in terms of leadership practices and models that have been inculcated in the organizations and became core values. Such perspective is presented in great details by Empson L. (2018) in her article, where she extensively provides elements linked to the insecurity of individuals, forcing them to work overtime and go the extra miles and meeting all expectations set by the organization, just to be accepted, to be the right fit in the role, to prove themselves worth being there.

The privilege in these situations seems to be on one single side, always a benefit of the company, never the value of the employee. This view fits the neoliberal leadership model mentioned above. Such attitude is inherited through the culture driven in the organization and as a human trait or personal predisposition. It seems, that the organizations are recognizing and preferring while recruiting such insecure professionals, as they are also bringing a second element, a success predictor for the goals and ambitions of the business. This wanted element that is in strong correlation to productivity and commitment is that they are all overachievers and helps the leader to target the maximization of profit. Overachievers are the low hanging fruits that the business needs and wants to have and nurture. Such individuals will prove themselves to be hard working, constantly ensuring they are bringing value to the business. They demonstrate a constant attitude of passion towards their activity and are genuinely convinced that they have a real contribution to the larger business goal. The insecurity of not knowing how much they can offer and how good they are, as professionals, keeps such employees at the verge of needing to show more, placing all they have in everything they are expected to deliver. For all obvious reasons, such achievers, overachievers indeed, are passionate or come across as being passionate, to the customers and their supervisors. They are the gems, blinded by their own shine.

Understanding that the existing research and sources of information, corroborated with the surveys available on the media knowledge, could always be considered as a sufficient source of intelligence to understand and further adjust the leadership practices. One element is always there ahead of all these, and that is the Time factor. The time and the relevance of the present. As history repeats itself, nevertheless, the future can never be predicted, unless there is a constant adjustment, a constant calibration of the practices. Understanding the past, keeping the curiosity on the present and current activities, these together will help better understand trends, patterns and predictable or predictive models. Observing and analyzing with most rigorous methods the status, this could surely be the right approach into welcoming the unknown with the right set of tools, instruments and mindset.

Rethinking leadership models became a burning topic of discussion due to pandemic and it is equally maintaining the level of intangibility, a high level of versatility and most of all, it is on a constant change. The definitions of leadership the numerous models proposed above as leadership styles, the practices adopted and reshaped over the years, the importance that it gained in the last few decades are all proofs of the importance and relevance of this concept. This concept will never reach an end state, as we can already see that it picked up in the business world as a major factor of influencing financials, business value, hence it is a major variable in any economical equation. 
Having these as the baseline for the current paper, the authors have defined a set of 15 interviewing questions that have been conducted in various sectors/ industries at top management positions mainly from outsourcing sector. There were 10 valid respondents from top managers from companies, with high importance on the outsourcing market, which hire more than 8000 people at national level. The interview was conducted directly. Therefore, we consider their answers relevant for our study.

The objective of the interviews was to identify and understand elements linked to the two dimensions announced in the introductory part of this paper (meaning the present and the future). In addition, the investigation was designed also for a more granular level, interrogating the people aspects from a leadership perspective, the business and value creation as goals to sustain economic health and the cultural shifts or practices.

Pandemic brought major changes in approaching people, the patterns of managing employees have been seriously affected, basis feedback of the organizations and corrective measures implemented at scale (for example: Wellbeing activities, counseling agencies as a free benefit, emotional resilience workshops on a weekly or monthly basis accessible to all employees, especially people managers, etc.). According to the results of the interview conducted, the ways of working, with the work from home impacting factor, has become the driver of adjusting leadership practices. More than this business models have also been challenged to ensure stability of their financial and at the same time to ensure no loss of knowledge, people fluctuation and other silent factors that are reflected in the economy of the sectors. Hence, leadership is the mechanism of keeping all pieces together for a healthy business, collaborative team, safe and positive work environment, adaptable organizational culture and, for the most ambitious ones, the driver for higher productivity. Summing it up, the key word for the internal drivers for economic success seems to be Leadership.

The current research is a continuation of the authors work and academic involvement from a recent research (Todoran \& Popa, 2020), conducted 6 months after isolation of 2020. During online or remote and virtual working, the authors have launched a questionnaire investigating the readiness to create a sustainable business model through Learning and Development practices, focusing at the time on the outsourcing industry.

Such a result or discussion is highly relevant in the leadership models, as developing leaders and individuals at scale is considered one of the pivotal elements for the sustainable business. At the time, the results reveled at very high predictability and readiness to invest in people growth, weather from within the company at no cost, or basis external functions and vendors. In all situations, the importance or creating a ready and adapted pool of professionals was a clear metric and goal of the organizations that took part in the study. Reiterating some relevant results obtained from the previous study mentioned in the above paragraph, the authors have revealed that there is a $40 \%$ readiness of the business leaders to adapt for online learning, meaning in the current paper, that the "future dimension is ready to absorb new learning practices. Another result on the questionnaire is that $9 \%$ ready to embrace and adapt for the future practices, meaning testing something completely new and not yet available in the current practices. Now this is not an impressive percentage for change and adaptability, but is a start for introducing new operating models. And most impactful factor was that 93\% consider that supporting and investing in educational programs, is in the core strategy of the outsourcing culture (basis authors past research available in the paper "Sustainability Through Learning And Development In Outsourcing Sector", publishes in the proceedings of ICESS 2020, (Todoran \& Popa, 2020)). As an overall conclusion and concept, further developed in the current paper, was that investing and growing potential within 
the existing talent of employees is necessary and organizations are ready to invest to attaining this goal.

The design and structure of the interview aimed to scan the perceptions of the business models from two main dimensions: the "now" of the practices and the "future" readiness. The "now" had a set of questions looking at the practices used currently, whereas the future dimension was testing the readiness of adapting, the innovative ways of changing leadership models. Some questions intersected the present and future expectations, hence a "now and future" dimension emerged. In terms of respondents, the scale was rather in terms of covering industries. Searching to identify multiple perspectives, interviewing a total of 10 representative leaders from banking, outsourcing, gas and energy and manufacturing companies, provided an insight of the "now" and "future". While investigating on the people element and leadership practices, the authors have addressed the questions on "what are the current ways of working?" and also recording a set of real examples and specific instances of innovative ideas from the day to day practices, in the current working environment, from a leader's perspective.

This element of innovation is also linked to the future dimension and readiness to adapt and adopt new practices, models of working and managing. In terms of managing teams and self-management, the questions were around the work from home scenario. These questions were in connection with the business realities of work performance, productivity, monitoring self and teams, tools and new technologies used. The status quo of this answers where shaping current practices, and providing a scheme of managing people and business. The readiness for change with an impact on business, people and culture were addressed from various angles looking at new and disruptive ways of working, automation and digitization measures, new metrics implemented to shift responsibility of productivity within the teams and at a softer and discrete level, the element of cultural changes.

\section{Results and discussions}

The current theoretical approach is bringing a set of insights on the vast scale of the leadership concept, basis a set of interviews conducted within selected industries, trying to understand and reshape the leadership models. The findings and results are a qualitative expression of the perceptions captured as relevant concepts to develop best practices, to be replicated or completely challenged in the future and unpredictable business context.

The outcomes are presented as a summary of factors linked to people, business and culture in the present and current time dimension, as a first set of data. The second part is the future state of the facts, the dimension of the unknown and the readiness and level of adaptability to adopt future and untested work scenarios. The second set of data is a representation of the creativity and innovation readiness of the leaders.

Below table is bringing a few elements that were relevant and outstanding while interviewing the market leaders: 
Table 1. Leaders perspective - interview on people practices for "now" and "future" business models

\begin{tabular}{|c|c|c|}
\hline Dimension Tested & Sample of Interview questions & Extract from response data base \\
\hline \multirow[b]{2}{*}{ NOW } & $\begin{array}{l}\text { Q1. Ownership and responsibility of the team: is } \\
\text { there anything new in the way your team is } \\
\text { delivering results? If yes, what has changed? }\end{array}$ & $\begin{array}{l}\text { "This is not much different from } \\
\text { before; it is just way easier to } \\
\text { discern doers from do not-ers." }\end{array}$ \\
\hline & $\begin{array}{l}\text { Q2. Team management and self- management - In } \\
\text { which way have you maintained your team's } \\
\text { productivity? How is their efficiency monitored? }\end{array}$ & $\begin{array}{l}\text { "The sudden change to a highly } \\
\text { decentralized structure pushed } \\
\text { everyone to the limit. The } \\
\text { employees had to adapt to a self- } \\
\text { regulated work pace and } \\
\text { managers had to review their } \\
\text { toolkit of monitoring and } \\
\text { engagement solutions." } \\
\text { "Monitoring had to be shifted } \\
\text { from process compliance (are you } \\
\text { doing things as required?) to } \\
\text { process outcome ( have you } \\
\text { delivered the expected results in } \\
\text { the expected timeframe ? )- and } \\
\text { this comes together with increased } \\
\text { empowerment. Like any change, } \\
\text { it suits some more than others." }\end{array}$ \\
\hline \multirow[t]{2}{*}{ FUTURE } & $\begin{array}{l}\text { Q3. New habits - What are the main characteristics } \\
\text { of the cultural changes and practices, if the case? }\end{array}$ & $\begin{array}{l}\text { "The remote working has created } \\
\text { a high level of anxiety and } \\
\text { confusion among the people. We } \\
\text { observe some setbacks - } \\
\text { aggressiveness, tendencies of } \\
\text { inefficient and cumbersome } \\
\text { communication, less } \\
\text { responsibility. We take this as } \\
\text { natural effect and work to setup } \\
\text { daily routines that could offset } \\
\text { these negatives: direct verbal } \\
\text { communication used more than } \\
\text { before, individual discussions, } \\
\text { intensive coaching sessions, etc." }\end{array}$ \\
\hline & $\begin{array}{l}\text { Q4. How is Business Value linked to the Leadership } \\
\text { tasks? How is the team involved in value creation? }\end{array}$ & $\begin{array}{l}\text { "The leader should be much more } \\
\text { of a facilitator, a conductor } \\
\text { enabling the team - orchestra to } \\
\text { deliver at its very best." }\end{array}$ \\
\hline Now and Future & $\begin{array}{l}\text { Q5. Automation and digitalization - What are the } \\
\text { main projects linked to digitization or automation, } \\
\text { affecting people practices? }\end{array}$ & $\begin{array}{l}\text { "Digitization and automation } \\
\text { should be viewed as means and } \\
\text { not goals per se, milestones and } \\
\text { not destinations in the journey of } \\
\text { business transformation." }\end{array}$ \\
\hline & & \\
\hline
\end{tabular}

Source: Authors' own research.

DOI: 10.2478/picbe-2021-0045, pp. 494-504, ISSN 2558-9652 |

Proceedings of the $15^{\text {th }}$ International Conference on Business Excellence 2021 
In terms of business and strategizing economic measures, there is a trending need of adjusting the business models for the new era, meaning digital and automation. Sustainability of the business model became more present in the decisions of companies leaders. In more practical terms, the tendency of changing the procedures, processes and the activities into a more machine dependent environment is where the business is aiming. Yet this is at the top-level strategic priorities and the measures taken seem to be a natural metamorphosis of the current practices. As one of the top managers in the banking industries rightly stated in his interview, processes that are streamlined and logical would naturally fall into the automation and digitization, with little challenges.

This implies a very important point, understanding the practices, ensuring a full visibility of the processes in the organization and accepting the current realities into fixing them in a natural and digital format. However, this is the perspective of the business, where the people are the users and the beneficiary of the new business model. Here is where leaders can create the difference: from an open and timely communication, into a clear setting of expectation and mostly ensuring that the changes are becoming part of the daily responsibilities of the employees. There is where the challenge lays, in in the changes related to the human mental state, which is translated here in the resistance to change, yet it is never a setback, for the visionary leaders, instead it is a new model of addressing them as a milestone towards a reshaped path to success. The benefit of doing so, setting such milestone in accepting change, can be done by pushing the responsibility, in the best shape and measurable forms into the hands of the individuals making them intrapreneurs at the workplace. The new model of leadership could be seen as a more responsible way of doing things at the workplace. The more the changes are implemented hands on at all levels, the better the outcomes, acceptance and the way the business shall reshaped the operational models.

According to the interviews conducted this is where potential failure and errors of implementations are spotted and adjusted with immediate action, little impact and ideally, minimum effort. Little needed to mention, that such corrections, if done or identified at the individual level, not pushes as a mandate from leadership, are an easy fix and less considered as a major failure, less criticized and changes will not be considered as another change, rather the needed fine tuning. Being proactive at the workplace can make the whole organization work better and be more productive.

Another perspective under discussion in the interviews was the cultural and behavioral element of handling business nowadays. Related to this we see intrapersonal competencies as combinations of knowledge, skills, abilities, and attitudes, that help leaders to recognize and engage in behaviors demanded or afforded by the leadership context. Examples of such competencies are abundant in the literature. Zaccaro, Green, Dubrow, and Kolze (2018) identified cognitive capacities that can emerge through leader development such as problem-solving skills, creative thinking, strategic thinking, wisdom, cognitive flexibility, and judgment and decision-making skills. All these are a good and complex mix to manage the work from home approach. The work from home standards, were nothing like the old standards. There were no attendance measures in place, for the micromanagers this was a major challenge to further keep deliverables under control, also the routines were impacted for both teams, individuals and leaders. The work was transformed overnight with no guidelines and no handout. Hence, employees at all levels have created their business reality. For some, awaiting instructions was natural, others would act on their own empowered by the business and own understanding of the needs and their role definitions, or at the extremes the overachievers (insecure or not, basis the theory stated above in the literature review) and the new category of employees emerged the "Netflix" employees, disturbed by amount of 
emails and tasks tagged to them. Such elements have created and redefined a new business culture and together with that a new leadership model, a set of compliance practices, new performance derived from the outcomes, discipline and even autonomy, in some cases, got impacted. The regular doing my job well, as everyone sees it, was reduced to one single expression of performance: The outcome and that too should ideally be measurable. The quantitative component of the productivity of the employees became more important.

Reverting to the second dimension, the future is not readily defined during pandemic and the leadership models are equally infant to their effect. That means that there is little room for failure when it comes to business. Financial and numbers must be maintained or even grown, yet people practices, psychological safety and mental state are part of the foundation of such outcomes and numbers. Metrics have been and will always be human dependent, as long as we are not replaced by robots, hence people are - as they say - "the most valuable assets". Investing in leadership and reshaping a healthy culture accepted and adopted by the employees as all levels, will ensure the future and the success of the business, regardless of the challenges and other unexpected effects of external factors, like another pandemic or global economical destabilizer. Enterprises are today obliged to build resilience against a high number of types of events that threaten the continuity of their business processes (Sahebjamnia et al., 2018).

\section{Conclusion}

The new ways of leading, the new models proposed for the future, can easily be debated in at least two ways. One: are we ready to adjust to whatever comes, and this is how we gear up? Or second option, we create the future as we prepare for it. We develop the realities of how we should act in the future, by shaping new practices, developing the culture and new values. It would be that we prepare for something that we create.

The future of the sustainable business, when it comes to leadership models for the people, rather than for the business, is focusing on values. Yet personal values may differ or be very intimate to ones self, as opposed to the business values (morals of financial values). We could say that the pandemic brought a higher focus on values at the firm level by searching and identifying them better than in the past. The recommendation of one respected leader from the banking industry sounds like one ready-made solution to be implemented, and I quote with his anonymous consent "Diversity of ideas, exchange of perspectives, individual contributions in a team - all have to be fostered by the leader, every day. Brewing these ingredients together should lead to a strategy definition. Communication is then critical to ensure engagement of the team to contribute further. Therefore, the leader should be much more of a facilitator, a conductor enabling the team orchestra to deliver at its very best."

If the past organizations used to have a strategy, a vision and even a mission basis, which, the entire ecosystem was built as a statement and the work, was done around those elements. The new model of business is more about the cultural feel and the actual outcomes, not so much about a statement and a slogan. That is still there as a brand, worth the prestige of the company and also for the employees, but for the work that is yet to be done, the outcomes are the true elements of value. Focus on the outcomes of the employees more than before, giving them more freedom in deciding their productivity it is the new component of the leadership model. Because of this, the leaders have it now easier than before in scanning the profiles of their team members. Now you may see the trusted, the involved and action man at work in one single project or task, and equally much draw the line of the batch where most attention and energy goes, where mentoring, facilitating or at times commanding some individuals is a must for them to take act and complete 
their jobs responsibilities.

In the literature regarding business environment there are a number of key success factors: adaptability, agility, communication, coordination, leadership, and technology application (Harrad, 2006; Zhou et al., 2017). These aspects were all found in conducted interview with companies' representatives and their responses to the crisis.

The summary of the research conducted above is: core values are more visible now in individuals. It is just a matter of observing and acknowledging them. Some natural psychological adverse reaction post pandemic are visible and they tend to go towards lack of responsibility and ownership, at times into rather less professional emotional reactions of aggressiveness and irritating attitudes, negativity in all new tasks and some more disarming behaviors are in less fortunate scenarios the composition of a team. This comes to underline the fact that the employees in order to be more efficient should be driven by common values regarding work and workplace. Adaptability and flexibility as values are part of the new rethought leadership model as changes come with a shock and the new work environment, working from home, has created an unprecedented shock, cultural swifts have become the side effect of the first major change in working styles. These have radically impacted the leadership practices are the new models being tested are almost like in an incubator mode, testing new leadership powers, nurturing people, dozing authority. The value system plays in the context a major role. The future is not yet at the horizon. The chain effect is at its peak now and taking imprudent decisions, like one size fits all or controlling and commanding styles are not part of the new leadership model. The concept of metacompetencies, as declared by Miclea in an interview conducted by Sabau. (2019) seem more relevant and needed now. Not doing that is ignoring the presence and surely not preparing for the future.

The research is not without limitations. First, usually business continuity and leadership models were associated with medium and large enterprises and our research is focused on big enterprises. We intend to extend our research on business continuity and leadership model for smaller enterprises to see the effects also for different dimensions. Second, our data was collected more from the business services sector and we plan for the future to extend our research for more sectors from the economic activity and to state owned companies.

\section{References}

Avolio, B. J., Walumbwa, F. O., \& Weber, T. J. (2009). Leadership: Current theories, research, and future directions. Annual Review of Psychology, 60(1), 421-449.

Charumilind, S., Craven, M., Lamb, J., Sabow, A., \& Wilson, M. (2021). When will the COVID19pandemic end?. Article. Retrieved from https://www.mckinsey.com/industries/health care-systems-and-services/our-insights/when-will-the-covid-19-pandemic-end.

Craven, M., Liu, L., Wilson, M., \& Myshore, M. (2021). COVID -19: Implications for business. Executive Briefing. Retrieved from https://www.mckinsey.com/business-functions/risk/ our-insights/covid-19-implications-for-business.

Colovic, A. (2021). Leadership and business model innovation in late internationalizing SMEs. Long Range planning $x x x(x x x x) x x x$ https://doi.org/10.1016/j.lrp.2021.102083.

De Smet, A., Rubenstein, K, Schrach, G., Vierow, M., \& Edmondson, A. (2021). Psychological safety and the critical role of leadership development. Survey. Retrieved from https://www. mckinsey.com/business-functions/organization/our-insights/psychological-safety-and-the-criticalrole-of-leadership-development. 
Empson, L. (2018). If You're So Successful, Why Are You Still Working 70 Hours a Week?. Harvard Business Review. Retrieved from https://hbr.org/2018/02/if-youre-so-successful-whyare-you-still-working-70-hours-a-week.

Ghoshal, S., Bartlett, C., \& Moran, P. (1999). A new manifesto for management. Sloan Management Review, 40(3).

Harrad, J.R. (2006) Agility and discipline: critical success factors for disaster response. The Annals of American Academy of political and social science, 604 (1), 256-272.

Howieson, W.B., Burnes, B., Summers, J.C., (2019). Organizational leadership and/for sustainability: Future directions from John Dewey and social movements, European Management Journal 37 (2019) 687e693.Johnson, R., \& Ouchi, W. (1974). Made in America (under Japanese management), Harvard Business Review, 52(5), 61e69.

Masayuki, M. (1998). The end of the 'mass production system' and changes in work practices. In H. Harukiyo, \& G. D. Hook (Eds.), Japanese Business Management: Restructuring for low growth and globalization. London: Routledge.

Meuser, J. D., Gardner, W. L., Dinh, J. E., Hu, J., Liden, R. C., \& Lord, R. G. (2016). A network analysis of leadership theory: The infancy of integration. Journal of Management Official Journal of the Southern Management Association, 42(5), 1374-1403.

Ospina, S., \& Foldy, E. G. (2010). Toward a framework of social change leadership. NYU wagner research paper No. 2010-05.

Parker, H., Ameen, K. (2018). The role of resilience capabilities in shaping how firms respond to disruptions. Journal of Business Research, 88, 535-541.

Petrescu, C. (1933). Patul lui Procust. Editura Eminescu.

Rezaei Soufi, H, Torabi, S., Sahebjamnia, N. (2019). Developing a novel quantitative framework for business continuity planning. International Journal of Production Research, 57(3), 779-800.

Sabau, C. (2019). Cele patru metacompetențe de care avem nevoie pentru ceea ce ne așteaptă în viitor. Retrieved from https://timponline.ro/cele-patru-metacompetente-de-care-avemnevoie-pentru-ceea-ce-ne-asteapta-in-viitor/.

Sahebjamnia, N., Torabi, S.A., Mansouri. S.A. (2018). Building organizational resilience in the face of multiple disruptions. International Journal of Production Economics, 197, 63-83.

Todoran, T., Popa, R.A. (2020). Sustainability Through Learning and Development in Outsourcing Sector. Innovative Models to Revive the Global Economy, Series: Proceedings of the International Conference on Economics and Social Sciences, 3, 295-303. https://doi.org/ $10.2478 / 9788395815072$.

Wallace, D.M., Torres, E.M., Stephen J. Zaccaro, S.J. (2021). Just what do we think we are doing? Learning outcomes of leader and leadership development, The Leadership Quarterly xxx (2021) Xxx.

Zaccaro, S. J., Green, J. P., Dubrow, S., \& Kolze, M. (2018). Leader individual differences, situational parameters, and leadership outcomes: A comprehensive review and integration. The Leadership Quarterly, 29, 2-43. https://doi.org/10.1016/j.leaqua.2017.10.003.

Zhou, X., Shy, Y., Deng, X., Deng, Y. (2017). D-Dematel: a new method to identify critical success in emergency management. Safety science, 91, 93-104.

Zhu, J., Song, L.J., Li Zhu, Johnson, R.E. (2019). Visualizing the landscape and evolution of leadership research. The Leadership Quarterly 30 (2019), 215-232. 